Artigo

\title{
Fumicultores e entidades de representação políitca: problemas públicos e engajamento em Santa Cruz do Sul/RS
}

\author{
Fabricio Teló ${ }^{2}$
}

Resumo: O objetivo do trabalho é analisar a participação de agricultores na relação que estabelecem com suas entidades de representação política. Para isso, elegeu-se como caso para estudo, um grupo de fumicultores do município de Santa Cruz do Sul/RS. O artigo trabalha com alguns problemas públicos construídos por esses sujeitos e por suas organizações e analisa como esses processos conformam os níveis de engajamento político e a definição de qual ou quais entidade(s) será ou serão escolhida(s) pelos agricultores como a(s) mais legítima(s) para atuar(em) na sua representação política.

Palavras-chave: fumicultores; representação política; engajamento; organizações; problemas públicos.

\section{Tobacco producers and political representation entities: public problems and engagement in Santa Cruz do Sul/RS}

Abstract: The aim of thispaper is to analyze farmer's participation in the relation that they establish with their political representation entities. To do it, we have elected as a case to study a group of tobacco producers of Santa Cruz do Sul/RS. The article

\footnotetext{
${ }^{1} \mathrm{O}$ artigo ora apresentado é parte da dissertação de mestrado defendida em 30/05/2014, sob a orientação da professora Leonilde Servolo de Medeiros, a quem o autor agradece imensamente pela atenção e empenho com que se dedicou no trabalho de supervisão da pesquisa. O autor agradece, ainda, a Juliano Florczak Almeida pela leitura e contribuição. Fonte de Financiamento: Trabalho desenvolvido com recursos do CNPq e da Faperj.

2 Programa de Pós-graduação de Ciências Sociais em Desenvolvimento, Agricultura e Sociedade (CPDA), Universidade Federal Rural do Rio de Janeiro (UFRRJ) - Rio de Janeiro - Brasil - fabriciotelo@hotmail.com
} 
deals with some public problems emerged by these people and by theirs organizations and analyses how these processes conform the levels of political engagement and the definition of which entity (or entities) will be chosen by the farmers as the more(s) legitimate to actuate in their political representation.

Keywords: tobacco producers; political representation; engagement; organizations; public problems.

\section{Introdução}

Os produtores de tabaco do município de Santa Cruz do Sul/RS contam com um rol relativamente diverso de organizações nas quais podem se engajar politicamente ou tão somente se vincular em uma relação menos próxima. A mais antiga delas é o Sindicato Rural (SR), fundado em 1945 com o nome de Associação Rural de Santa Cruz do Sul. Atualmente é a entidade que, segundo a legislação sindical, representa o patronato. A Associação dos Fumicultores do Brasil (Afubra) foi fundada em 1955 e tem como um dos principais objetivos a gestão de um seguro mútuo para a lavoura dos produtores contra os prejuízos causados pelas chuvas de granizo que ocorrem frequentemente. O Sindicato dos Trabalhadores Rurais (STR) foi fundado em $1962 \mathrm{e} \mathrm{tem} \mathrm{como} \mathrm{um} \mathrm{dos} \mathrm{principais} \mathrm{trunfos} \mathrm{a} \mathrm{conquista} \mathrm{do}$ direito à aposentadoria rural. Por fim, o Movimento dos Pequenos Agricultores (MPA) foi construído em Santa Cruz no final dos anos 1990 e início dos anos 2000. Suas principais pautas foram o crédito agrícola e a habitação rural.

Embora a relação entre os fumicultores e essas organizações seja atravessada por um conjunto diverso de elementos, como a prestação de serviços assistenciais, as relações pessoais com as lideranças e o atendimento no "balcão" das organizações, este artigo tem como foco a análise do reconhecimento dado pelos agricultores ao trabalho de cada entidade na publicização dos problemas e de como isso interfere na vinculação desses sujeitos às entidades. Embora o conceito de problemas públicos tenha sido formulado anteriormente por outros autores (Gusfield, 1981), utilizarei nesta análise a definição elaborada por Daniel Cefaï, que, nos seus diversos escritos, procurou aprofundar o conceito para os diversos contextos de ação coletiva. Baseado em uma abordagem pragmatista ${ }^{3}$, o autor chama atenção para a dimensão pública da ação coletiva. Sua questão de fundo é a centralidade atribuída à noção de público. Para isso, o autor chama atenção para a "publicidade" da ação coletiva, no sentido de evidenciar a dimensão dramatúrgica e retórica da atuação dos atores políticos e a relação disso com a definição das identidades coletivas. Ele propõe englobar a interação estratégica (aquela da micromobilização) em uma concepção de "arena pública" a fim de superar o entendimento de ação

${ }^{3}$ De acordo com o Cefaï (2009: 14), o procedimento pragmatista é aquele que acompanha as experiências e perspectivas dos atores sociais: “A questão de base não recai mais sobre os 'determinantes estruturais' e os 'cálculos racionais' da ação: substitui a platitude da ação instrumental por arquiteturas complexas da situação, da pessoa e do coletivo". 
coletiva como atividades decorrentes de uma junção de interesses individuais com um objetivo em comum, típica da Teoria da Mobilização de Recursos ${ }^{4}$ (McCarthy; Zald, 1977).

O autor considera as redes e organizações como contextos de experiência e de ação se realizando, de modo que ganha importância a análise das experiências que os atores vivenciam no cotidiano e como eles as veem. O lugar onde se faz a política, nesse sentido, são os locais onde as pessoas se encontram pelos motivos mais triviais na sua vivência cotidiana: "As vias de acesso à arena pública passam por regimes de engajamento não públicos" (Cefaï, 2011: 74). Assim, se considerarmos o político como algo ligado apenas às organizações e instituições políticas, dotadas de formalidade, tudo o que está fora disso é considerado não político. Para a abordagem aqui adotada, no entanto, essa fronteira que delimita o político do não político é constantemente deslocada, uma vez que as redes de sociabilidade, que fazem parte do cotidiano informal das pessoas (o "não político"), têm uma importância decisiva para o mundo da política no sentido das organizações e instituições. No caso dos agricultores de Santa Cruz, esses espaços são as visitas entre os vizinhos, a convivência nas bodegas, as celebrações religiosas dominicais, a convivência no âmbito do centro comunitário ${ }^{5}$, dentre outros. A preocupação do autor, em última instância, é identificar o que provoca interesse em uma ação coletiva: "O que mantém juntas as pessoas, a que elas se prendem e o que as faz se prenderem” (Cefaï, 2009: 25).

De maneira semelhante, Thompson (1998) também já havia chamado atenção para essa dimensão postulando que é a partir das experiências, ou seja, das práticas cotidianas, que os indivíduos formulam sua visão de mundo e, a partir disso, podem vir a se constituir como classe. Comerford (2003) também realizou análises etnográficas desses tipos de espaços não institucionalizados em que ocorre a ação política. Esse autor estudou os espaços de sociabilidade para além da dimensão institucional e constatou que eles exercem influência decisiva sobre os espaços institucionais, tendo em vista a carga de valores morais e de reputação que é avaliada pelos agricultores em relação às lideranças sindicais.

De modo semelhante a Snow (2001) e Snow et al. (1986), Cefaï considera que o desafio dos movimentos sociais é converter mal-estares pessoais em causas coletivas, no contexto de uma arena pública, para onde apontam os atores coletivos e onde emergem novos universos de sentido. Dessa forma, ganha importância em sua teoria a dimensão afetiva da ação coletiva: "É ela que garante nosso contato com os outros e com as coisas e o que mantém unidas as situações nos situando nelas. A ação coletiva não está toda no agir, mas também no sofrer e no compartilhar" (Cefaï, 2009: 31). É também na percepção de que o próximo está sentindo as mesmas emoções, que, aos poucos, vai se criando a identidade coletiva que leva ao agir também coletivo.

\footnotetext{
${ }^{4}$ A Teoria da Mobilização de Recursos considera a agregação de recursos, como dinheiro e trabalho, um elemento central para compreender as atividades dos MS.

${ }^{5}$ No município de Santa Cruz do Sul, as localidades geralmente possuem um salão comunitário, onde as pessoas se reúnem aos domingos e dias festivos para praticar jogos e outras atividades de lazer.
} 
Cefaï (2001) chama a atenção ainda para a necessidade de ir além das narrativas dos líderes, ideólogos ou jornalistas em relação aos movimentos sociais e levar em conta também o que dizem os participantes que constituem a base de tais organizações, suas redes conceituais e suas tramas narrativas. Essa assertiva está congruente com a proposta deste trabalho, uma vez que o objetivo é justamente analisar as narrativas das "pessoas comuns" ${ }^{6}$ das organizações, as formas como elas enquadram suas entidades representativas e identificar quais conceitos e interpretações estão orientando suas ações, que interesses estão conduzindo à adesão aos movimentos e quais interações estratégicas estão constituindo as arenas públicas em que ocorre a ação coletiva.

Outra contribuição de Cefaï (2001) é a constatação de que os graus de adesão e conversão aos movimentos sociais, bem como os níveis de engajamento e participação são extremamente variáveis, da mesma forma como há variações também no uso que os atores fazem das diversas identidades que podem ser acionadas. Dependendo das circunstâncias, há contradições, sincretismos, paradoxos e ambivalências. Nesse sentido, a emergência de problemas públicos gera um processo de disputas no âmbito das arenas públicas, as quais, de acordo com a definição do autor, possuem três elementos caracterizadores. O primeiro é a importância das organizações, entendidas como mobilizações coletivas e dinâmicas de institucionalização inseridas em um contexto de atuação dramatúrgica ${ }^{7}$. Cefaï, Veiga e Mota (2011) apontam, portanto, para a necessidade de descrever as performances públicas, sejam as participações dos indivíduos em reuniões ou manifestações, sejam as tomadas de posições dos porta-vozes das organizações, ou até mesmo estratégias de silêncio ou boicote a determinadas atividades. Mas, para além disso, enfatizam que "[...] é preciso descrever, se possível etnograficamente, as atividades fora de cena (que vão dos simples laços de sociabilidade entre vizinhos ou amigos às preparações em segredo das estratégias políticas adotadas)" (Cefaï; Veiga; Mota, 2011: 41). Nesse sentido, as teorias até então elaboradas sobre a ação coletiva (tais como a Teoria da Mobilização de Recursos, a Teoria das Organizações, das Redes, dentre outras) não são suficientes. É necessário levar em conta também outras fontes de análise até então negligenciadas por essa literatura, como a antropologia das relações de parentesco, o estudo das comunidades locais, a análise dos simbolismos religiosos, a etnografia da comunicação comum e a microssociologia dos espaços públicos (Cefaï; Veiga; Mota, 2011: 42).

\footnotetext{
${ }^{6}$ Por meio dessa expressão, Martins (2012: 11-12, grifo nosso) chama a atenção para a importância de se colocar a cotidianidade da vida das pessoas comuns como foco da investigação sociológica, pois, segundo ele, "[...] é nos limites, nos extremos, na periferia da realidade social que a indagação sociológica se torna fecunda [...]. É nesses momentos e situações de protagonismo oculto e mutilado dos simples, das pessoas comuns [...] que a sociedade propõe ao sociólogo suas indagações mais complexas, seus problemas mais ricos, sua diversidade teoricamente mais desafiadora."
}

${ }^{7}$ Chamando atenção para a dimensão da dramaturgia no comportamento cotidiano, evidenciada por Goffman, Cefaï (2001) considera o mundo social como uma cena pública em que os atores realizam atuações performáticas. 
A segunda característica das arenas públicas são as associações ${ }^{8}$ como formadoras de problemas públicos através dos temas que estabelecem como pauta. A forma com que elas chegam a esse resultado foi denominada pelos autores como "teatros do sentimento e da opinião", uma vez que a associação unifica os sentimentos e opiniões de seus membros e os externaliza ao público (ou à arena pública) de um modo dramatúrgico, interferindo, assim, na opinião pública e nas agendas midiáticas. A emergência de um problema público, portanto, "[...] envolve afetividades, sensibilidades e moralidades; envolve experimentações de sentimentos de amor, de ódio, de medo, de injustiça [...]" (Cefaï; Veiga; Mota, 2011: 42). A terceira característica está relacionada à importância das associações como atores constituintes das "redes de políticas públicas", em que o Estado incentiva a institucionalização das organizações políticas a fim de servirem como mediadoras de políticas públicas.

Sob a inspiração de Comerford (2003), Cefaï (2001, 2009) e Quirós (2010), a metodologia utilizada para a elaboração desta pesquisa foi uma etnografia de três meses em uma comunidade de Santa Cruz, onde se buscou analisar, na vivência conjunta do cotidiano, como se dava o fazer político desses sujeitos, quais eram os valores que orientavam sua organização, sobre quais pautas eles conversavam nos momentos de interação e que assuntos eram destacados por eles nas conversas estabelecidas comigo, para além dos temas sobre os quais eu fazia perguntas. Antes desse período de imersão no cotidiano dos agricultores, passei dois meses residindo no centro da cidade, entrevistando lideranças e pesquisando sobre a dinâmica da produção de tabaco e me familiarizando com as pessoas para melhor adentrar ao campo especificamente. As ferramentas metodológicas utilizadas foram a elaboração de um diário de campo a partir das observações do dia a dia e a realização de entrevistas informais com colonos e lideranças.

Selecionamos alguns problemas que apareceram com mais intensidade durante o trabalho de campo e que ocupam espaços de centralidade na arena pública da fumicultura para serem discutidos neste artigo: o preço do fumo, o granizo, a necessidade de previdência social, os financiamentos e a ameaça da proibição da continuidade do cultivo.

\section{0 problema do preço do fumo}

Embora sejam muito frequentes as falas que enaltecem a fumicultura como a cultura financeiramente mais rentável proporcionalmente à área de terra utilizada, nem sempre os agricultores inseridos nessa atividade se satisfazem com a renda que auferem com a venda do produto. Desde o início do século os

${ }^{8}$ O termo aqui se refere não apenas a organizações formalmente constituídas, mas às diversas possibilidades de agrupamentos e acordos entre indivíduos em vista de algum objetivo. 
colonos $^{9}$ vêm se associando (e, em algumas situações, se mobilizando, como é o caso das "greves" ${ }^{10}$ ) em torno do problema do preço do fumo. Atualmente, a média do preço estabelecido no acordo entre as suas entidades de representação e as empresas é único para todos os produtores. Então, quando um fumicultor não é bem-sucedido, geralmente todos os outros também não são. Isso facilita que os colonos atribuam ao preço um sentido de coletividade ou de público.

Esse tema é objeto de conversas no cotidiano dos fumicultores e nos momentos de sociabilidade: antes e depois das celebrações religiosas, jogos, festas, visitas entre vizinhos, encontros na rua, conversas de "bodega" etc. Com isso, eles percebem que se em um ano um produtor tem uma baixa rentabilidade, isso não é um azar apenas dele, mas é um problema que atinge todos e que possui causas a serem combatidas, ou seja, para além da lei da oferta e da procura, há também a dimensão da vontade política de pagar bem ou não.

Um dos fatores que podem gerar diferenciação entre os fumicultores é a classificação das folhas do tabaco. Enquanto um pode ter uma quantidade maior de folhas consideradas de boa qualidade (BO1), outros poderão ter uma quantidade menor. Tudo isso depende também da sorte de vender o fumo em um dia em que a empresa determina a seus classificadores que eles podem "comprar bem", ou seja, ser menos rígidos e qualificar como $\mathrm{BO} 1$ boa parte da mercadoria. Pode haver outros dias - não raros - em que a determinação é de que os classificadores "comprem mal" e considerem apenas uma parte muito pequena do fumo como BO1 e o resto como de qualidade inferior, mesmo tendo boa qualidade. A classificação, portanto, depende menos das propriedades objetivas das folhas do que de um jogo entre fumicultores e fumageiras, que repõe a tensão em cada momento de comercialização do fumo. Trata-se de um jogo em que normalmente as regras são ditadas pelas empresas. Daí a importância das greves, que invertem essa ordem usual.

Por ser um tema que afeta fortemente a vida e as expectativas dos agricultores, a questão do preço do fumo é considerada relevante pelas quatro entidades citadas neste trabalho: a Afubra, o SR, o STR e o MPA. A Afubra foi a que primeiro pautou esse problema. Esse foi um dos elementos que fizeram com que os produtores reconhecessem essa associação como uma entidade que os representava na tentativa de solucionar o problema do baixo rendimento trazido pela atividade nos momentos de crise. Nem sempre, porém, a forma como ela se posicionava em relação às empresas agradava a todos. Nesse sentido, várias foram as situações em que recebeu críticas, sobretudo por parte do STR e do MPA.

\footnotetext{
${ }^{9}$ Colono é a categoria utilizada pelos próprios agricultores para se autodefinirem. Seyferth (1993) chamou atenção para a dimensão étnica da identidade camponesa do Sul do Brasil expressa pela categoria colono. Ao mesmo tempo em que ela possui uma conotação de campesinidade, representa também uma "origem" europeia, seja ela alemã, italiana, polonesa, dentre outras. Para além da dimensão étnica, a autora identificou um conjunto de características necessárias para o sujeito ser considerado colono: possuir uma fração de terras, produzir alimentos para o próprio consumo e ter um pertencimento tradicional à comunidade rural.

${ }^{10} \mathrm{Em} 1986$ e em 1989, os fumicultores entraram em "greve", ou seja, pararam de entregar o produto às firmas e fizeram piquetes para impedir que os fumicultores que não tinham aderido à greve entregassem. A utilização do termo greve não é por acaso: sinaliza a incorporação do repertório do operariado urbano como uma forma legítima de ação política.
} 
Nos anos 1970, o STR começou a questionar publicamente a forma como a Afubra estava conduzindo, através dos acordos com as empresas, a negociação do preço do fumo e passou a ser também ele um ator importante com o qual os fumicultores poderiam se identificar no intuito de resolver o baixo rendimento monetário da fumicultura. Em 1973, o STR contratou um professor de Economia, Armando Hennig, para realizar um estudo técnico a fim de apontar os custos de produção e, com base neles, qual deveria ser o reajuste do preço do fumo. A conclusão a que chegou foi a de que o reajuste no preço da safra de 1974/5 deveria ser de 84,7\%. O acordo firmado entre Afubra e empresas, no entanto, previa um aumento de apenas $40 \%$. Com esses dados em mãos, o STR reivindicou que se fizesse uma reunião na sede da Fetag, em Porto Alegre, da qual participariam representantes do Sindicato das Indústrias do Fumo, da Afubra, da Farsul, do Ministério da Indústria e Comércio, da Secretaria de Agricultura e dos STRs de Santa Cruz do Sul e Candelária (Liedke, 1977). Um trecho da resposta da Afubra, no jornal Gazeta do Sul (edição de 26/11/1974), sintetiza o posicionamento da entidade em relação a essa disputa:

Concluindo, temos a satisfação de registrar, sem qualquer agitação ou incitação da Ordem Social Brasileira ${ }^{11}$, que a comercialização do produto fumo junto aos compradores é tranquila, a preços cada ano melhores, o que provam os substanciais aumentos de área de nossos fumais e um aumento de novos plantadores a cada ano (grifo nosso).

Ainda que o STR não tivesse poder político para forçar um recuo das empresas na negociação do preço do fumo e tampouco contasse com uma conjuntura favorável para promover uma mobilização dos agricultores, esse questionamento foi importante, pois a partir dessa iniciativa as negociações do preço do fumo passaram a ser realizadas com a presença de entidades sindicais, de modo que hoje as reuniões são feitas entre representantes das empresas e dos agricultores, representados pela Afubra, pela Fetag-RS e pela Farsul e respectivas federações de Santa Catarina e Paraná.

Na safra de 1975/6, houve outro momento de divergência entre Afubra e sindicatos da Fetag-RS, dessa vez em torno do número de classes do fumo que determinam o preço a ser pago ao produtor. Conforme Montali (1979), o Ministério da Agricultura baixou, em 1975, a portaria de $n^{\circ} 674$, que aumentava de 28 para 49 o número de classificações. Os STRs iniciaram um processo de resistência e reivindicavam a redução de 49 para 21, por acreditarem que uma quantidade muito alta de classes facilitaria às empresas o pagamento de valores baixos aos produtores. A Afubra, por sua vez, defendia a manutenção do número, uma vez que, segundo a autora, a proposta havia partido justamente do Sindifumo (Sindicato Interestadual da Indústria do Tabaco - atual Sinditabaco) em conjunto com a Afubra. Dois anos depois, em 1977, um dirigente do STR fez a seguinte reflexão:

${ }^{11} \mathrm{O}$ destaque à não subversão da "Ordem" evidencia a influência da repressão política que o regime militar impunha no período em questão. 
Talvez o inimigo maior que o preço, o granizo, o vento ou as pragas, seja a classificação. Acontecia sempre que, em anos anteriores, os classificadores diminuíssem o fumo na escala de qualidade, isto é, pegavam o fumo de uma classe mais cara e diziam que era de outra, inferior [...] A situação melhorou apenas no decorrer da última colheita, quando fiscais da própria Secretaria da Agricultura punham-se ${ }^{12}$ nas portas das firmas e acompanhavam o processo de classificação, fazendo justiça para quem estava do lado mais fraco da corda, o colono (dirigente do STR ao Jornal Gazeta do Sul de 12/11/1977).

Ainda hoje os processos de classificação são motivos para discussão entre os fumicultores. Em função dessa característica de pouco enfrentamento da Afubra em relação às empresas, o MPA também se constituiu como um ator crítico à posição dessa entidade. Especialmente no que se refere às reuniões de estabelecimento do preço do tabaco, a crítica é que haveria um processo de cooptação da Afubra por parte das empresas, gerando prejuízos para os fumicultores, que receberiam um valor mais baixo pelo fumo produzido em função da falta de pressão política por um preço mais alto. Uma chacota relatada por alguns agricultores sobre esse aspecto é a seguinte: "A Afubra é como uma galinha. Quando chega perto do galo (as empresas do setor fumageiro), senta e abana o rabo"13.

Ainda que a Afubra dispute capital político em outro plano, que não o da contribuição sindical ${ }^{14}$, o que está em jogo para ela é a legitimidade perante os produtores, as empresas e a sociedade em geral de se colocar como a entidade de maior ou menor representatividade dos fumicultores. Embora, nos últimos anos, minimizada, a relação entre MPA e Afubra tem sido de intensa disputa. Enquanto esta representa os fumicultores em uma relação de apoio e parceria com as fumageiras, aquele considera que a exploração por elas é o que impede as melhorias para o setor e, portanto, considera-as como antagonistas que devem ser combatidas.

Com a realização de diversos protestos e mobilizações em massa de fumicultores do município e da região, o MPA se firmou como um movimento de forte contestação às empresas e, nesse sentido, passou a ser uma alternativa de organização no sentido de solucionar, mesmo que parcialmente, o problema do preço, tendo em vista suas ações mais enérgicas e impactantes, como ocupação dos pátios de empresas, do Sinditabaco, marchas pelo centro da cidade, com queima de folhas de fumo etc.

\footnotetext{
${ }^{12}$ Por reivindicação dos agricultores organizados em torno do STR.

${ }^{13}$ Embora esta frase não faça sentido em todas as regiões do Brasil pelo fato de as pessoas não considerarem que uma galinha tenha rabo, ela faz sentido para os colonos de Santa Cruz e, por isso, decidi mantê-la, por ilustrar a compreensão de um segmento de colonos a respeito da submissão da Afubra em relação às fumageiras, tal qual a submissão de uma galinha a um galo. Todavia, a despeito destas críticas feitas tanto pelos colonos quanto por trabalhos acadêmicos - com destaque para Vogt (1997) e Iorio (1993), dentre outros -, seria um erro afirmar que os fumicultores não se sentem representados pela Afubra, pelo menos em alguns aspectos.

${ }^{14}$ Ela não precisa disputar a adesão dos agricultores em termos de contribuição financeira já que ela é a única que oferece um serviço indispensável para os fumicultores, o seguro mútuo da lavoura, a partir do qual capta recursos.
} 
O simples fato de a entidade considerar o preço do fumo uma pauta importante não é suficiente para fazer com que os produtores se identifiquem com ela. O que percebemos na pesquisa é que não é o fato de pautar o preço que aproxima os fumicultores das entidades, mas a forma como cada uma o faz e, dessa forma, dependendo da perspectiva política de cada agricultor e da conjuntura do momento, haverá a identificação com uma ou outra. Produtores mais apegados ao cumprimento das normas sociais e avessos à transgressão da ordem estabelecida pelas empresas tendem a se identificar mais com a Afubra e os dois sindicatos que compõem o conjunto das entidades oficiais de negociação; produtores menos apegados ao cumprimento das normas e menos avessos à transgressão dessa ordem tendem a se identificar mais com o MPA, tendo em vista a maneira com que cada entidade se posiciona frente a esse problema.

A dimensão moral, portanto, assume centralidade na determinação da vinculação dos agricultores a cada entidade. Transgredir as normas implica em colocar em xeque a própria reputação, pois haverá um julgamento dos pares a respeito do comportamento adotado. Nesse sentido, para um colono assumir uma relação de identificação e engajamento com o MPA, por exemplo, implica em arcar com as consequências de uma quebra de valores e normas que organizam a vida na colônia, sobretudo em se tratando do caráter tido como radical das estratégias de mobilização adotadas pelo Movimento. Corre-se o risco de ser malfalado entre os vizinhos, de ser enquadrado como um baderneiro ou um louco, de ter comprometidas as relações com vizinhos, parentes e amigos etc.

Para Snow et al. (1986), o engajamento das pessoas é condicionado a uma série de crenças: 1) que o problema em questão é sério; 2) que o culpado pelo problema é a pessoa (ou entidade, sistema, grupo, enfim) apontada pelo Movimento, bem como que a causa do problema é aquela apontada pelo MS; 3) que há um antagonista a ser combatido e é também aquele informado pelo MS; 4) que há possibilidade de mudança e que a ação coletiva é eficaz nesse sentido;5) que é necessário permanecer "em pé", ou seja, com firmeza e empenho. Esse conjunto de convicções faz com que se torne secundário o risco de se ter a reputação maculada por participar de ações que representam quebras de valores e, nesse sentido, o vislumbrar de uma conquista futura passa a compensar as dificuldades e riscos inerentes ao engajamento.

Em suma, o preço do fumo, combinado com os critérios de classificação, tem sido pauta prioritária da maior parte das mobilizações dos fumicultores. Se pudéssemos fazer uma analogia com os processos reivindicatórios dos trabalhadores assalariados, poderíamos dizer que a demanda por um preço melhor pelo fumo é paralela à demanda pelo aumento salarial, que é o elemento mais estimulante das mobilizações, por se tratar de um fator decisivo para a reprodução material das pessoas. Ele tem sido, portanto, objeto de disputas políticas no âmbito de diversas arenas públicas construídas pelos fumicultores e seus mediadores ao longo do tempo, desde o início do século até os dias atuais. 


\section{0 granizo}

No Sul do país, não é rara a ocorrência de granizo, causando sérios prejuízos aos produtores - em certos casos, perda total da produção, de modo que a frequente ocorrência desse fenômeno tornou-se, em um determinado período, um problema público central na vida dos fumicultores. Sempre que ocorre uma chuva de granizo, todos procuram saber quem foi atingido na comunidade, no município e na região. Sempre que algum colono é atingido, há uma forte comoção por parte dos vizinhos, pessoas próximas e também por parte de pessoas mais distantes. Após a chuva, os vizinhos todos vão conferir as lavouras uns dos outros para ver como ficou a situação. Para os que foram atingidos, a ideia é também servir como apoio e consolo. Esses espaços de interações entre vizinhos no momento "pós-chuva", quando as perdas estão sendo contabilizadas, são decisivos para o compartilhar de uma mesma experiência e para a energização do processo de tornar público o problema.

Cefaï et al. (2011) chamam atenção para a importância da dimensão afetiva na construção de problemas públicos. O relato de Dona Marta ${ }^{15}$ (agricultora que já teve sua lavoura atingida) evidencia esse processo: "Dá uma tristeza tão grande quando acontece isso com a gente... Dá vontade de jogar tudo pro alto, porque é um ano inteiro de trabalho jogado fora. É muito triste mesmo". Se não houvesse essa insatisfação que envolve o plano dos sentimentos, o problema do granizo teria mais dificuldades para se tornar público.

Havia, então, a necessidade de os fumicultores encontrarem não necessariamente uma solução - já que o granizo é um fenômeno natural impossível de ser controlado -, mas uma amenização dos efeitos desse problema que, tornado público, constituiu, junto com o preço do fumo, um dos principais estímulos à criação, nos anos 1950, da Afubra. Essa entidade, portanto, produziu um sistema de seguro baseado no princípio do mutualismo, em que todos contribuem com um pequeno valor, que é destinado a um caixa comum. Quando ocorre granizo na propriedade de algum associado, causando perda na produção, parte desse valor arrecadado é destinada a este proprietário em forma de reparação aos prejuízos. Em função disso, a grande maioria dos produtores paga a taxa do seguro da Afubra, ou seja, se torna um associado da entidade. Na maior parte dos casos, nem é necessário ir até a sede da entidade para fazer o pagamento. No pacote do contrato firmado com a empresa fumageira, já está incluída a taxa do seguro. Existe, portanto, um acordo entre a Afubra e as fumageiras em que estas recebem a taxa paga pelos produtores e repassa à entidade. $\mathrm{O}$ valor da taxa é incluído no pacote de insumos (fertilizantes, herbicidas e fungicidas) e equipamentos utilizados durante a safra, cujo valor é descontado no momento da venda do tabaco.

Sabourin (2011) destaca que as associações tornam possível a atualização de estruturas de reciprocidade ou a transferência de recursos provenientes de sistemas

\footnotetext{
${ }^{15}$ Os nomes das pessoas com quem foi estabelecida interação durante o trabalho de campo foram substituídos por pseudônimos a fim de evitar possíveis constrangimentos.
} 
de troca para um contexto de redistribuição. De certa forma, é isso que a Afubra está fazendo, na medida em que recupera parte dos princípios de solidariedade típicos do associativismo cristão.

Em síntese, a tentativa de minimização do problema do granizo foi encaminhada no âmbito das Semanas Ruralistas ${ }^{16}$, com a criação de uma entidade, hoje Afubra, que criou um sistema de seguro mútuo em que cada produtor pode se associar ou não. Esse foi, portanto, um dos fatores decisivos que garantiram sua consolidação enquanto entidade importante para os fumicultores, reconhecida inclusive pelas demais entidades representativas, e é principalmente isso que motiva a vinculação dos produtores a ela: uma garantia de que não terão todo o investimento de uma safra perdidos no caso de serem atingidos por um evento que gere perda total na lavoura.

\section{A aposentadoria}

A ausência do direito à previdência social para os trabalhadores rurais começou a ganhar publicidade como um problema nos anos 1940, quando houve as primeiras tentativas de articulação das lutas por direitos, espalhadas nos diversos espaços do país. Foi apenas em 1971, porém, que houve um primeiro avanço, quando o governo Médici criou o Programa de Assistência ao Trabalhador Rural (Prorural - Lei Complementar no 11 , de 25/05/1971), que previa a aposentadoria de meio salário para os homens após os 65 anos de idade ou por invalidez e previa ainda auxílio-doença, assistência médica e odontológica, pensão por morte e auxíliofuneral. Maduro (1990) destaca que a Fetag-RS foi uma das organizações que reivindicaram a criação de um programa como esse. Sobre isso, Paulo Henrique, 83 anos, ex-presidente do STR de Santa Cruz do Sul, relata:

Para conseguir o meio salário mínimo na época não foi necessário fazer esses protestos. O que sim foi necessário foi a realização de reuniões com as autoridades, principalmente federais - e eu participei de algumas delas - porque era na época da ditadura militar e nessa época nem admitiam grandes mobilizações. Não tinha. A questão era negociando diretamente com os chefões. (Paulo Henrique, entrevista ao autor, Santa Cruz do Sul, 22/04/2013).

O Estatuto do Trabalhador Rural, aprovado em 1963, já previa um fundo de Assistência e Previdência Rural (Funrural), mas a sua operacionalização efetiva só ocorreu a partir da criação desse programa. O fato de os STRs atuarem na mediação desse programa de assistência social os fortaleceu significativamente, pois os agricultores faziam uma associação direta entre o sindicato e o recebimento

\footnotetext{
${ }^{16}$ As Semanas Ruralistas eram eventos municipais organizados pela Igreja Católica em convênio com o Ministério da Agricultura, que duravam de três a quatro dias, para os quais eram convidados os agricultores e suas esposas para ouvirem palestras proferidas por agentes do referido Ministério e do clero sobre temas como conservação do solo, o incentivo ao associativismo rural, a cultura da soja, do milho, do trigo e o incentivo à policultura (Rodeghero, 1997).
} 
do benefício, de modo a gerar um sentimento de gratidão e reconhecimento. Embora o direito à aposentadoria não fosse o único, pois o STR mediava também diversos serviços de assistência (médica, odontológica, veterinária e jurídica), este foi o que pareceu ter tido mais peso político.

Esse processo, marcado pela característica da negociação, foi encampado especialmente pela Contag e suas federações, em boa medida legitimadas pelo fato de que os trabalhadores urbanos já tinham conquistado esse direito naquele período. Depois de conquistado o direito, "[...] ah, aí o sindicato cresceu. Nós estávamos no início com 464 sócios. Já no ano de 1972, nós chegamos quase a dez mil associados e só homens" (Paulo Henrique, entrevista ao autor, Santa Cruz do Sul, 15/04/2013).

Embora estejamos falando de um direito - o que não pressupõe a retribuição de um favor -, os colonos tomam o acesso à aposentadoria como um dom, tal como proposto por Mauss (1925/2003), de modo que o fato de se associar e pagar as anuidades representa uma espécie de retribuição ao fato de o sindicato ter mediado o acesso à aposentadoria. $\mathrm{O}$ referido autor explica sua teoria em termos de sistemas de prestações totais ${ }^{17}$, regidos por uma normatização que envolve três obrigatoriedades: dar, receber e retribuir, sem que isso seja concebido (ao menos publicamente) pelos indivíduos como uma obrigatoriedade. Esses três tipos de ações devem ter um caráter, pelo menos aparente, de voluntariado e generosidade. É bem-visto e prestigiado quem toma iniciativas de dar presentes sem nunca ter recebido antes da pessoa para quem está doando e é malvista a pessoa que se nega a receber um presente de alguém. Quanto mais alguém dá, mais prestígio recebe e, consequentemente, mais poder conquista. Isso é central para compreendermos os processos de vinculação dos agricultores às entidades em questão. Quanto mais serviços elas prestam, mais prestígio conquistam e mais poder político elas acumulam. O "dom" do acesso à aposentadoria, portanto, rendeu ao STR mais prestígio, legitimidade, um crescimento muito grande no número de associados e, consequentemente, mais poder político.

Durante os anos 1980 e início dos 1990, a pauta principal passou a ser a extensão do direito de aposentadoria também às mulheres agricultoras, que passaram a reivindicar seu espaço de participação nas decisões dos sindicatos, federações e confederação com a finalidade de protagonizar a luta pelo seu reconhecimento profissional e digna de receber os mesmos direitos que os homens. $\mathrm{O}$ direito à aposentadoria das agricultoras foi reconhecido em 1988 com a Constituição, porém o INSS não efetuava os pagamentos. A pressão para que o direito fosse realmente efetivado teve que se estender até 1992. Em Porto Alegre, por exemplo, no dia 11 de fevereiro daquele ano, a Fetag-RS liderou uma grande mobilização em torno da pauta da previdência.

\footnotetext{
${ }^{17}$ Para entender melhor o conceito de sistema de prestações totais, é bom relembrar outro, que é considerado o principal legado teórico do autor, o conceito de fato social total, aquele em que se exprimem "[...] de uma só vez as mais diversas instituições: religiosas, jurídicas e morais - estas sendo políticas e familiares ao mesmo tempo; econômicas - estas supondo formas particulares da produção e do consumo, ou melhor, do fornecimento e da distribuição; sem contar os fenômenos estéticos em que resultam esses fatos e fenômenos morfológicos que essas instituições manifestam” (Mauss, 1925/2003: 187).
} 
Essa não foi o único problema público que o STR ajudou a construir. Ele também teve atuação em torno de outras pautas, tais como as questões das políticas de preço mínimo, crédito agrícola, fundiário, habitacional e, sobretudo, das políticas de assistência social. Isso foi muito importante na conquista de vários direitos e é utilizado hoje como uma forma de atualização da prática da troca de dons e contradons, conforme a lógica da reciprocidade. A questão, porém, é que essas outras frentes de ação não estão presentes na memória dos colonos com quem conversei a respeito do STR. A principal lembrança que os fumicultores têm dessa entidade no que se refere à luta por soluções de problemas é o empenho que este e os demais sindicatos ligados à mesma federação tiveram nas lutas pela conquista do direito à aposentadoria. Um agricultor, que já foi participante ativo do MPA, reflete: "Nos anos 1970 a grande finalidade do STR era lutar pela aposentadoria e estão colocando isso até hoje como 'valor do STR"'. De acordo com a sua interpretação, o STR ainda busca a construção de seu reconhecimento em cima dessa questão da aposentadoria e não inova na luta em torno de outras pautas com o mesmo empenho.

É assim que hoje, conforme informações de uma liderança do STR, cerca de $80 \%$ dos seus associados são aposentados, ou seja, pessoas que foram beneficiadas pelas lutas travadas por esse sindicato, ou ainda pessoas que provavelmente participaram de mobilizações e/ou de discussões em torno dessa questão. Os agricultores mais jovens de hoje, que não estiveram inseridos na construção do problema público da aposentadoria, tendem a não perceber o sindicato como um instrumento de organização através do qual podem buscar a solução de problemas públicos, tal como o fizeram os agricultores dos anos 1970 e 1980.

Estão demonstrando isso quando decidem não se filiar ao sindicato, já que, conforme percebi durante a pesquisa, a primeira coisa que surgia na memória dos agricultores quando eu falava em sindicato era a ideia do "lugar onde se encaminha a aposentadoria" e o lugar onde se tem acesso a consultas médicas, odontológicas e veterinárias a um preço mais acessível, "então, para que eu vou pagar o sindicato, se eu consigo fazer as consultas pelo SUS? E para se aposentar, uma vez precisava ser sócio para conseguir aposentadoria. Hoje em dia nem precisa mais, então para que gastar esse dinheiro ${ }^{18}$ ?." Em geral, os que adotavam tal discurso tinham entre 35 e 55 anos. Em contrapartida, os associados, em sua maioria idosos, justificavam a manutenção do vínculo principalmente em função dos descontos nas referidas consultas. $\mathrm{O}$ discurso mais recorrente se construía nos seguintes termos:

É bom ser sócio do sindicato porque quando a gente precisa de um médico, a gente vai nos médicos e dentistas que atendem dentro do sindicato, que custa uns 30 reais a consulta ou a gente pode ir em um particular conveniado com o sindicato e paga só $50 \%$ da consulta. Também quando tem um animal doente na propriedade é só chamar o veterinário do sindicato, que ele vem por um preço mais barato (Falas frequentes dos colonos).

${ }^{18}$ Referindo-se ao dinheiro gasto na taxa que os associados precisam pagar anualmente para manterem ativa a matrícula de sócio. 
Esse tipo de serviço assistencial tem assumido importância significativa na vida dos colonos, especialmente se levarmos em consideração a precariedade dos serviços de saúde oferecidos pelo Estado ao longo do tempo. Alguns agricultores até apontaram que o atendimento pelo Sistema Único de Saúde (SUS) tem melhorado nos últimos anos, o que teria diminuído a necessidade de "pagar o sindicato". De fato, o município de Santa Cruz, em função da alta carga de impostos que arrecada com as exportações de tabaco, consegue investir um volume significativo de recursos para a saúde ${ }^{19}$, o que proporciona algumas melhorias nos atendimentos via SUS. Tradicionalmente, porém, o atendimento via STR era considerado superior. O STR consolida-se, portanto, como a entidade que pode reivindicar para si os créditos de uma conquista de fundamental importância para os agricultores: a aposentadoria rural. Embora não seja a única, é a que mais tem se mostrado relevante para os agricultores.

\section{Os financiamentos}

$\mathrm{O}$ acesso a linhas de crédito para financiar a produção do tabaco tem sido também uma questão de grande importância e tem gerado disputa nas arenas públicas em torno da definição dos rumos da política agrícola para a fumicultura. Os colonos salientam a necessidade que eles têm de financiamentos que viabilizem a sua inserção no sistema integrado de produção, que lhes permita comprar equipamentos com tecnologia mais avançada, investir na manutenção/ampliação da infraestrutura da propriedade, enfim, que lhes permita ter um capital de giro para administrar a produção.

A principal linha de crédito acessada por eles tem sido o Pronaf - Programa Nacional de Fortalecimento da Agricultura Familiar, criado no ano de 1995, que constitui hoje a principal política pública brasileira voltada à agricultura familiar. Durante a pesquisa, os colonos contaram que, até o início dos anos 2000, quem mediava o Pronaf eram as agroindústrias processadoras do tabaco, que utilizavam o nome dos produtores, e elas mesmas encaminhavam a solicitação do financiamento ao agente financeiro. Segundo os produtores, as empresas recebiam os recursos a um juro de $4 \%$ ao ano e repassavam para os colonos a um juro de $8 \%$, apropriando-se desse percentual extra ${ }^{20}$. Silva $(2007: 140)$ relata como se dava esse processo:

Entre vários papéis que o agricultor assinava na presença do orientador agrícola, representante da empresa com que o agricultor transacionava seu fumo, estava a procuração para que a empresa ingressasse com o pedido de empréstimo para o agricultor.

\footnotetext{
${ }^{19}$ De um total de $\mathrm{R} \$ 345.360 .841,26$ orçados para o ano de 2014 , $\mathrm{R} \$ 113.737 .856,58$ (32,93\%) serão destinados à Secretaria Municipal de Saúde. É o setor que mais recebe investimentos no município. Em segundo lugar vem a Secretaria de Educação e Cultura, que recebe 20,79\%. A Agricultura, por sua vez, está na outra ponta da lista com apenas 1,33\% do orçamento (R \$ 4.579.131,99). Fonte: Projeto de Lei no 245/E/2013 - Câmara Municipal de Vereadores de Santa Cruz do Sul.

${ }^{20}$ Não foi possível confirmar esses valores percentuais através de documentos oficiais. O que estou apresentando é baseado nas falas dos produtores. Entretanto, números à parte, o importante é o processo que estava em jogo naquele contexto.
} 
Dessa maneira, a dependência que eles tinham em relação às agroindústrias era muito maior. Eles recebiam esse recurso no início da safra como que "para passar o ano" e depois esse valor era descontado no momento da venda do fumo. Se um produtor tivesse algum problema com a empresa com a qual estava estabelecendo a integração produtiva e ela decidisse não encaminhar o financiamento, o produtor teria que mudar de empresa ou então ficar sem financiamento.

Nesse sentido, a principal pauta utilizada pelas lideranças do MPA, quando iniciaram a construção do movimento em Santa Cruz, foi a possibilidade de encaminhamento direto do Pronaf sem a mediação das empresas, o que iria possibilitar o pagamento de um juro mais baixo e diminuir as restrições nos critérios de elegibilidade dos beneficiários do programa. Essa foi uma das principais pautas que mobilizavam os fumicultores a participarem das manifestações promovidas pelo MPA. Vitor Marcelo, que ajudou a construir o Movimento, relata: "Essas coisas levavam os agricultores para a rua para fazer protestos etc.. Com essa conquista, foram poucos os agricultores de Santa Cruz que não encaminharam um pedido de financiamento do Pronaf através do MPA. Os colonos contam que, no início, as lideranças dessa organização visitaram a quase totalidade dos agricultores do município. Reuniam grupos de vizinhos na casa de um produtor e faziam uma reunião para explicar como funcionava o Pronaf e já aproveitavam para dar início ao processo de encaminhamento do pedido e falar sobre a importância de participar das ações de luta. Dessa forma, a demanda pelo acesso direto ao Pronaf foi adquirindo, aos poucos, o caráter de público, à medida que passou a ser objeto de conhecimento comum e de discussões coletivas nos diversos espaços de sociabilidade.

Foi assim que o MPA conseguiu se consolidar na região, tanto em termos de legitimidade e reconhecimento dos agricultores, por ter conquistado o acesso mais direto a uma política que tem melhorado significativamente sua qualidade de vida, quanto em termos de recursos financeiros, já que uma pequena porcentagem do valor financiado fica com a associação criada para viabilizar a operacionalização desse serviço. Isso evidencia um processo que Kunrath e Schmitt (2012) chamam de institucionalização dos movimentos sociais e que tem se intensificado, sobretudo, no pós-redemocratização, período em que está havendo uma aproximação entre Estado e organizações da sociedade civil ${ }^{21}$.

\footnotetext{
${ }^{21}$ Giugni e Passy (1998) contribuem para entender este processo através da ideia de cooperação entre Estado e organizações sociais. Eles elencam três maneiras distintas de relação de ajuda recíproca (ou trocas políticas): 1) consulta: quando os atores estatais buscam as organizações para consultá-las a respeito de um determinado assunto que seja de domínio exclusivo da organização, geralmente em função do fato de a organização possuir informações exclusivas a respeito do público que ela representa; 2) integração: quando os atores da sociedade civil passam a integrar o conjunto dos atores que elaboram as políticas públicas; 3) delegação: quando o Estado delega funções às organizações sociais com vistas à implementação de determinada política, como é o caso do Pronaf, do Programa Nacional de Habitação Rural (PNHR) e das políticas assistenciais no âmbito do Prorural desde os anos 1970. Estas três maneiras distintas de cooperação estão elencadas de acordo com a intensidade da relação, ou seja, a delegação de tarefas é o nível mais intenso de cooperação e, nesse sentido, quanto maior o nível de cooperação, maior será o grau de alterações nas configurações organizativas das entidades participantes e, por consequência, nos distintos mecanismos de aproximação entre entidades e base social.
} 
O STR, portanto, nesse contexto, perdeu espaço tendo em vista o fato de que não deu ao crédito agrícola a mesma atenção dada pelo MPA. O Vale do Rio Pardo é uma das regiões do país que mais encaminham Pronaf. Em Santa Cruz do Sul, por exemplo, conforme dados do Anuário Estatístico do Crédito Rural (Banco Central do Brasil, 2012), no ano de 2012, foram assinados 3.285 contratos do Pronaf, totalizando um valor de $\mathrm{R} \$ 21.056 .959,47$ de financiamento nas categorias Custeio e Investimento. Em Venâncio Aires, no mesmo ano, 1.930 agricultores acessaram o programa, o que somou um valor de $\mathrm{R} \$ 20.985 .208,28$ financiados. No Estado do Rio Grande do Sul, neste mesmo período, foram assinados 304.226 contratos e disponibilizados R 3.786.568.707,60 em recursos. De acordo com Grisa, Wesz Junior e Buchweitz (2014), dos R\$ 97,6 bilhões disponibilizados entre 1999 e 2012, $24 \%$ foram aplicados no Rio Grande do Sul, o que mostra a importância que o programa assume para as entidades enquanto mediadoras.

Nesse sentido, o principal elo que liga os agricultores de Santa Cruz ao MPA é o reconhecimento pela conquista do acesso a uma política que promoveu mudanças nas suas vidas e a manutenção desse vínculo é, em boa medida, sustentado pela mediação que o MPA realiza até hoje para sua obtenção. O Pronaf não é a única política mediada pelo movimento. Outras como o Programa Nacional de Habitação Rural - PNHR também cumpre um papel semelhante ao do Pronaf em termos de aproximação dos agricultores, porém a abrangência desse programa em termos numéricos, é inferior ao Pronaf, que tem sido o carro-chefe na atuação do MPA.

O reconhecimento pela conquista de tal programa passou a ser objeto de disputa entre as entidades de representação política dos agricultores. Vendo o tamanho do crescimento do MPA com a mediação do Pronaf, as entidades concorrentes começaram a traçar estratégias para minimizar a perda de espaço que esse processo lhes estava gerando. A relação estabelecida entre o MPA e o STR, portanto, que já era complexa em função da disputa por capital político gerada pelo fato de se proporem como representantes de um mesmo público, adquiriu o caráter de uma disputa ainda mais intensa ${ }^{22}$.

Em Santa Cruz do Sul especificamente, a relação é marcada por constantes tentativas de deslegitimação de uma entidade pela outra, especialmente depois do crescimento do MPA no município, que "roubou" boa parte da base social do STR, ao promover um processo de desvinculação de um número significativo de agricultores que deixaram de ser sócios do STR para compor a base social do MPA.

Esse processo fez com que o STR passasse por um processo de reavaliação de sua política de criar dificuldades para seus associados encaminharem os pedidos de financiamento por meio do sindicato, como vinha sendo até então. Antes de o MPA iniciar o processo, já era oficialmente possível encaminhar pelo STR, porém era considerado praticamente impossível dadas as dificuldades impostas

\footnotetext{
${ }^{22} \mathrm{O}$ público representado por essas entidades é praticamente o mesmo, mas com algumas diferenças: enquanto a Contag representa oficialmente o conjunto dos trabalhadores rurais, incluindo posseiros, arrendatários, parceiros e os assalariados, o MPA foi criado com o intuito de representar apenas os pequenos agricultores, especificamente aqueles que possuem uma porção (pequena) de terra, como proprietários ou como arrendatários.
} 
pelo presidente da entidade que, utilizando o discurso da prudência para evitar que os colonos se endividassem, preferia não desincentivar o acesso ao programa.

Apesar das críticas, a mediação do Pronaf se tornou tão importante em termos de estratégia política das entidades que agora as quatro estão se colocando como mediadoras. A Afubra, que até meados de 2013, restringia-se ao Pronaf Florestal2 ${ }^{23}$, passou a mediar também o PronafCusteio, uma das modalidades mais procuradas, o que também intensificou a relação de concorrência ente Afubra e MPA. O SR desde 2005 também começou a mediar o programa, o que estabeleceu uma relação de concorrência também entre o MPA e o SR. É importante ressaltar que atualmente não está mais sendo possível solicitar recursos via Pronaf para financiamento da atividade fumícola, em função da Convenção-Quadro para o Controle do Tabaco (CQCT), que será tema do próximo item deste artigo. Os produtores de Santa Cruz, portanto, acessam o programa, mas solicitando recursos para outras finalidades, sobretudo para produção de milho, reforma de galpões, compra de juntas de bois e demais atividades que são realizadas paralelamente à fumicultura.

Os colonos, por sua vez, não são obrigados a manter vinculações permanentes com cada entidade em função da mediação do Pronaf. Como a cada ano é feito um contrato novo, quando o financiamento encaminhado por uma entidade é pago, o contrato está finalizado e o agricultor tem a liberdade de escolher, de acordo com os mais variados critérios, qual entidade será sua mediadora para o encaminhamento da solicitação do Pronaf do ano seguinte.

Em suma, a mediação do Pronaf tem sido, nos últimos anos, um elemento central para entender a participação dos agricultores nas suas entidades de representação. Ela adquiriu tamanha importância que, se uma entidade se nega a realizar tal serviço, ela é considerada atrasada e perde uma oportunidade de aproximar mais agricultores para a sua base social. Embora nem todos os agricultores encaminhem a solicitação de acesso ao Pronaf através do MPA, o Movimento é reconhecido pelos colonos de Santa Cruz como a organização que mediou a construção da necessidade dessa política como um problema público e lutou pela conquista da possibilidade de acesso dos fumicultores a essa política.

\section{"Querem acabar com o fumo"}

A principal questão levantada pelos fumicultores, durante o trabalho de campo, estava relacionada às diversas iniciativas dos setores contrários à prática de fumar, no intuito de criar instrumentos que promovam a redução gradativa da produção de tabaco no Brasil. Eu diria que este é o principal problema trazido como questão pública pelos fumicultores nos últimos anos. Ainda que, de uma forma ou de outra, tenha sempre estado presente, a questão começou a ser mais

\footnotetext{
${ }^{23}$ Segundo um membro da diretoria da entidade, a Afubra foi a primeira organização no Brasil a mediar o Pronaf Florestal. Esse protagonismo é fruto da preocupação da entidade com a questão do consumo de lenha para a secagem do fumo, que gera muito desmatamento. Esta modalidade do Pronaf, portanto, financia o reflorestamento com mudas de árvores que podem ser derrubadas, especialmente o eucalipto.
} 
evidenciada no início dos anos 2000 com o debate acerca da assinatura da CQCT pelo governo brasileiro ${ }^{24}$.

Dentre as medidas de implementação da convenção pelo governo brasileiro, as principais são o aumento pelo Ministério da Fazenda de impostos cobrados das empresas do setor do tabaco; a tentativa de proibição pela Agência Nacional de Vigilância Sanitária - Anvisa de adicionar aditivos químicos nos cigarros, de modo a diminuir a dependência dos consumidores; a obrigatoriedade da divulgação nas carteiras de cigarro de fotos de pessoas atingidas pelos malefícios causados pelo consumo de cigarro; a criação de um programa de incentivo à diversificação produtiva por parte do Ministério do Desenvolvimento Agrário e a restrição de crédito para agricultores familiares cuja renda provinda da fumicultura seja maior do que $80 \%$ da renda total.

Esse processo gerou uma situação de quase pânico nas regiões cujas economias giram em torno da produção e industrialização do tabaco. Os fumicultores passaram a se sentir ameaçados e perseguidos enquanto categoria profissional. Era recorrente ouvir da grande maioria dos colonos frases como: "O que vamos fazer sem o fumo aqui? Temos uma vida inteira de investimentos nessa atividade. Planto fumo desde os oito anos de idade. Aprendi com meu pai, que aprendeu com meu avô e assim vai...” Durante o trabalho de campo, era comum ouvir dos produtores: "Por que só o fumo? Por que não proíbem o álcool também? Faz tão mal quanto o fumo! Saiu uma pesquisa esses dias que diz que o açúcar e o sal matam mais que o cigarro, então por que só nós?”. Note-se que a construção do problema passa pela comparação do fumo com outros produtos e também pelas interações que os agricultores estabelecem com agentes externos, que trazem informações de fora, ou ainda através do acesso a meios de comunicação em geral.

Os colonos procuram rebater também os argumentos que caracterizam a fumicultura como uma atividade que traz malefícios à saúde tanto dos produtores quanto dos consumidores, especialmente em função da utilização de agrotóxicos:

Se tu fores ver no arroz, os caras usam mais veneno do que nós! No pimentão, nos tomates, na couve-flor... Vai ver esses hortifrutigranjeiros quanto veneno eles não usam nas coisas que eles plantam! E isso que é alimento, que depois vai para a mesa das pessoas! Antigamente, sim, o pessoal usava venenos fortes no fumo, mas hoje em dia é pouca coisa que vai (Seu Ramon e Dona Rafaela, Linha Bonita - Santa Cruz do Sul, conversa com o autor, setembro de 2013).

\footnotetext{
${ }^{24}$ Desde os anos 1960, no âmbito das Nações Unidas, o combate ao tabagismo tem sido uma questão importante, mas foi apenas nos anos 1990 que ações mais objetivas começaram a ser pensadas a nível internacional. Assim, em 1999, na 56 Assembleia Mundial da Saúde, deliberou-se pela realização de um tratado internacional em que os países que aderiram ao acordo se comprometeriam a estimular ações de controle e redução da produção e consumo do tabaco. Depois de quatro anos de negociação, a CQCT foi aprovada por unanimidade por outra assembleia, em 2003, com a presença de 192 países que, no mesmo ano, iniciaram os processos de ratificação. O Brasil assumiu uma posição importante na condução da construção da convenção e, em 2005, o Senado brasileiro a ratificou.
} 
Há uma identificação da região do Vale do Rio Pardo com a produção de tabaco. Sirvo-me da fala de um técnico agrícola da Emater do município em uma palestra para os beneficiários do PNHR no STR de Santa Cruz: "No Rio Grande do Sul, cada região tem o seu forte. Os gringos lá da Serra são mais fortes na fruticultura, o pessoal do Norte é mais forte na soja e no milho, na região Oeste tem mais arroz, na Campanha é o gado e aqui o nosso forte é o fumo". Ele evidenciava a importância de os produtores terem as suas propriedades com uma produção diversificada, especialmente em função do contexto da CQCT, mas afirmou a importância de se garantir o direito à continuidade da produção do fumo, "o forte" da região. Propor a interrupção da fumicultura em Santa Cruz, portanto, é propor que essas pessoas parem de fazer o que elas melhor sabem, daí a intensidade da reação às iniciativas da CQCT e a necessidade de tais medidas serem adotadas gradualmente.

Diante disso, as quatro entidades de representação assumiram a defesa da fumicultura como uma pauta importante, cada qual, porém, com empenhos e enfoques diferenciados. A Afubra é a que mais tem se empenhado nesta causa, especialmente depois da intensificação dessas discussões. Para isso, estabelece uma relação muito forte de parceria com o Sinditabaco, que também é uma das principais forças na defesa da fumicultura.

Se, por um lado, poucas iniciativas de contestação às empresas têm sido tomadas pela entidade, por outro, ela se empenha significativamente na defesa da continuidade da prática da fumicultura, especialmente frente às ameaças de proibição do cultivo dessa planta desde o início das discussões relacionadas à CQCT (Mengel, 2010). Na entrevista realizada com o presidente da entidade, por exemplo, mesmo sem tocar no assunto, o debate acerca das restrições que a CQCT visa estabelecer foi trazido à tona. $\mathrm{O}$ objetivo do dirigente era reforçar o argumento de que a fumicultura não pode ser extinta devido à sua importância socioeconômica para centenas de municípios que dependem dessa atividade produtiva e para milhares de trabalhadores que, direta ou indiretamente, dependem dela para se sustentar.

Nesse sentido, em função basicamente da defesa da fumicultura e do seguro mútuo contra o granizo, a Afubra tem se consolidado como uma organização muito respeitada e estável, com possibilidade de realização de várias iniciativas e projetos sociais. Como exemplo, destaca-se o projeto Verde é Vida ${ }^{25}$. A Afubra ocupa ainda, através de seu secretário geral, a Presidência da Câmara Setorial do Tabaco junto ao Ministério da Agricultura, um cargo de fundamental importância para a cadeia produtiva, já que é no âmbito dessas câmaras que são construídos os Atos Normativos que organizam boa parte do funcionamento de cada setor.

\footnotetext{
${ }^{25}$ Conforme a gerência de assuntos ambientais da entidade, através desse projeto, técnicos da Afubra desenvolvem atividades de educação ambiental nas escolas de educação básica dos municípios em que há produção de tabaco. A principal questão trabalhada por estes técnicos é o reflorestamento. Esta escolha temática está diretamente relacionada ao alto grau de desmatamento gerado pela fumicultura em função do consumo de lenha para alimentar os fornos das estufas utilizadas na secagem das folhas. Para além da educação ambiental em si, este projeto visa, em última instância, promover uma conscientização a respeito da reposição de árvores (especialmente o eucalipto) para garantirem a própria viabilidade econômica da fumicultura.
} 
O STR e o SR também têm assumido com força a defesa da atividade, porém a Afubra acaba se destacando. Afinal, esta tem como base apenas os fumicultores, diferentemente daqueles, que, embora tenham sua base composta majoritariamente por produtores de fumo, representam também as demais categorias de agricultores do município, ou seja, se os fumicultores deixassem de existir a Afubra não teria mais sentido, ao passo que os sindicatos teriam as demais categorias para representar. Sobre isso o presidente do SR afirma:

Temos feito parcerias com outras entidades em favor da fumicultura, do tabaco. [...] as entidades sempre estão ao lado do produtor para que não termine a produção do fumo na nossa região, porque nós entendemos que no momento não há nenhum produto que substitua a fumicultura. Então nós também estamos trabalhando na diversificação da lavoura. Nós entendemos que a monopolização da lavoura não é boa em estágio nenhum [...] Tem que ter mais que uma atividade. Quando uma não favorece talvez a outra possa favorecer (entrevista ao autor, Santa Cruz do Sul, 22/04/2013).

O caso do MPA demonstra a força que a cultura do fumo tem na região. No Plano Camponês, projeto político defendido pelo MPA, não haveria lugar para um tipo de produção nos moldes da fumicultura, em função da subordinação a que os produtores são submetidos na relação com as agroindústrias processadoras do tabaco, através do sistema de produção integrada, ou sistema de integração produtiva. Tendo em vista, porém, o fato de que, na região de Santa Cruz, ser contrário à fumicultura é quase uma blasfêmia, o MPA teve que adaptar seu discurso para poder dialogar com os agricultores, pois, se utilizasse um discurso semelhante ao utilizado pelos defensores da CQCT, de modo algum conseguiria se inserir na região. Certa vez, um agricultor comentou: "E os caras do MPA ficam falando mal da Afubra, já ouvi também comentários que já falaram mal do fumo. Eu não sei, não.... Isso demonstra que, por mais que o MPA tivesse por objetivo promover transformações nos frames dos agricultores no sentido de passar a cogitar a mudança de atividade produtiva, a dificuldade para tal meta é muito grande na medida em que a fumicultura é um valor muito arraigado na cultura desses colonos e é sua principal fonte de renda, de modo que a própria defesa da fumicultura torna-se um dos principais elementos que garantem legitimidade à organização.

Esse processo ilustra a reflexão feita por Cefaï (2007) a respeito da necessidade das organizações de ação coletiva se dobrarem às ordens de interação (aceitar as regras do jogo) que regem os comportamentos dos atores, sob a pena de serem percebidos como ofensivos e não serem reconhecidos caso não o façam. O MPA, portanto, não declara ser contrário à fumicultura, mas também não encampa com tanto empenho a sua defesa, tal como o fazem as demais entidades. Ao contrário, participa, no âmbito do Ministério do Desenvolvimento Agrário (MDA), do Programa Nacional de Diversificação em Áreas Cultivadas com Tabaco. Criado em 2006, o programa estimula a diversificação como uma medida de incentivo à redução 
da produção do fumo, uma das medidas adotadas pelo governo brasileiro para viabilizar a CQCT. Isso demonstra como os agricultores impõem suas questões às organizações, por mais que eles nem sempre estejam totalmente engajados a elas.

Várias foram as iniciativas tomadas pelas entidades no intuito de defender a possibilidade de continuação da fumicultura. Em 2004, antes da aprovação da assinatura pelo Senado, a Afubra e a Fetag-RS promoveram uma grande manifestação, com a presença de fumicultores dos três estados do Sul, num total de cerca de 10 mil pessoas no parque da Oktoberfest, por ocasião de uma audiência pública sobre a CQCT com a presença de alguns senadores.

Mais recentemente foi aprovado pela Assembleia Legislativa do Rio Grande do Sul um projeto de lei apresentado pelo deputado Heitor Schuch (ex-presidente do STR de Santa Cruz e da Fetag-RS), cujo objetivo era instituir o Dia Estadual do Produtor de Tabaco. O primeiro ano em que a data foi comemorada foi 2013. A Afubra, em conjunto com a Fetag-RS e com a Farsul e com o apoio do Sinditabaco, promoveu uma festa com o lema "Orgulho de fazer parte desta cultura", que contou com a participação de mil e trezentos produtores. O objetivo é tornar público para a sociedade a importância econômica da atividade e valorizar os produtores para que eles percebam a força que o setor possui e vejam que a sua cultura está sendo defendida.

Há, portanto, uma identificação muito forte dos agricultores com as entidades que defendem a atividade. Nas conversas com os colonos era perceptível como eles se identificavam como produtores de fumo. O termo aqui - se fumicultores ou produtores de fumo - não vem ao caso, porque o termo que eles usam para se referirem a si mesmos é colono. Importa é que, para eles, a ameaça à fumicultura é uma ameaça a eles mesmos, à sua identidade, uma ameaça à possibilidade de reprodução de suas propriedades e o risco de ter toda uma vida de investimentos perdida.

As agroindústrias do fumo, por sua vez, também incorporaram a pauta da diversificação em suas agendas e fortaleceram, junto aos fumicultores, as já existentes campanhas de estímulo ao desenvolvimento de outras atividades agrícolas e utilizam dessas campanhas como uma forma de desenvolver as "ações de responsabilidade social" e minimizar as críticas que recebem, especialmente dos atores contrários ao tabagismo. Ou seja, depois de uma quase avalanche de críticas à monocultura do tabaco, as empresas se apropriaram da pauta da diversificação. Elas a utilizam inclusive para fortalecer a própria fumicultura na medida em que a apresentam como uma das atividades (no caso, a mais rentável - e isso é central) no bojo do processo de diversificação produtiva que as famílias são incentivadas a iniciar.

A análise da diversificação produtiva não é central para nosso estudo. Contudo, foi trazida para a discussão tendo em vista a importância que ela tem assumido para a arena pública em que é disputada a possibilidade ou não da continuidade da fumicultura e para o direcionamento das ações de boa parte dos atores envolvidos no contexto que está sendo analisado nesta pesquisa. 
Esse problema público em torno da Convenção-Quadro foi central na pesquisa. A defesa do direito de continuar plantando fumo é fundamental para os colonos porque se refere, no limite, à defesa da sua existência enquanto categoria de trabalhadores. Mas não apenas isso. O que está em jogo aí vai além de uma questão material. Atinge a identidade desses colonos, que se reconhecem enquanto produtores de fumo e que percebem essa atividade como boa parte de sua razão de ser.

\section{Considerações finais}

As discussões apresentadas neste trabalho apontam para a importância das questões do cotidiano na conformação das organizações. Tais questões podem ou não se transformar em problemas públicos, dependendo da mediação de atores que se constituem como lideranças dos processos associativos. Elas se tornam "públicas" quando passam a ser objeto de discussão dos diversos espaços de interação, que também se dão no cotidiano. Em Santa Cruz, esses espaços eram a saída das celebrações religiosas, a bodega, os jogos de loto, futebol, bocha, os encontros no ônibus que vai até a cidade, as visitas entre vizinhos, as festas comunitárias, os enterros, dentre outros. Disso decorre a importância de se identificar quais são as questões que efetivamente afetam a vida dos colonos para se compreender as diferentes formas de engajamento e desengajamento nos diversos espaços de participação política.

No que se refere aos vínculos entre os fumicultores e as organizações políticas, as constatações da pesquisa nos levaram a inferir que, na medida em que os fumicultores, a partir de processos de interação cotidianos, passam a perceber uma questão como coletiva e observam uma entidade atuando em favor daquela questão, a aproximação e a identificação com ela tornam-se uma tendência forte. Nesse processo, a organização também passa por uma transformação provocada pelo próprio engajamento dos agricultores que, ao interpelar a agenda da organização com suas demandas, passa a ser parte da sua construção, em conjunto com as lideranças. Ao mesmo tempo, as organizações também podem, dependendo da situação, provocar mudanças (ou reenquadramentos) nos fumicultores que se engajam em seus projetos políticos. Ideias incogitáveis podem passar a ser cogitáveis depois do engajamento. Foi o caso, por exemplo, da realização de piquetes e acampamentos na frente das fumageiras, por ocasião das greves do final dos anos 1980, e das mobilizações promovidas pelo MPA. Há outras situações, no entanto, em que não há mudanças nos frames dos colonos. As mobilizações contra a CQCT, por exemplo, têm sido as mais ilustrativas de processos em que o objetivo não é reivindicar transformações na sociedade, mas a conservação de determinadas possibilidades.

Para nenhuma das entidades, a luta por um bom preço a ser pago pelo fumo foi fator decisivo na sua consolidação enquanto entidade de representação, já que era pressuposto básico. Como vimos, o fator decisivo para a Afubra foi o seguro 
mútuo, para o STR foi a aposentadoria e para o MPA foi o encaminhamento do Pronaf. No caso do SR, o que garantiu a sua consolidação enquanto entidade não foi a luta pela solução de nenhum dos problemas elencados anteriormente, mas as baixas taxas cobradas de seus associados para ter acesso aos serviços de assistência médica, odontológica e veterinária.

Os agricultores não veem como uma contradição a vinculação a entidades que criticam uma à outra em função de projetos políticos divergentes. Eles as percebem como importantes no que elas podem contribuir para a melhoria de sua realidade. Eles reconhecem os pontos fortes de cada uma e as valorizam a partir disso. "O STR é mais diplomático e o MPA é mais de fazer pressão", ou seja, cada entidade é boa em determinada ação e todas são importantes para eles, porque eles realmente precisam dos serviços e oportunidades oferecidos por cada um deles. A disputa que ocorre entre as lideranças, portanto, não tem a mesma importância para as "pessoas comuns", que, ao final, são representadas de diferentes formas pelas diversas entidades e, a partir do reconhecimento do trabalho que elas fazem, orientam suas decisões de engajamento ou desengajamento nas suas mobilizações e/ou no seu quadro de associados.

Essas constatações nos fazem questionar a própria noção de representação política, tendo em vista que, no cotidiano da colônia, a primeira ideia que aparece para os agricultores, quando se fala de sindicatos e organizações políticas, é da prestação de serviços e não a da representação política propriamente dita. Embora se possa considerar a prestação de serviço como uma forma indireta de representação política, não se pode tratá-las como se fossem a mesma coisa. Isso não significa que em certas ocasiões eles não se sintam representados por elas. O caso da CQCT ilustra bem o contrário. O que quero enfatizar é que a dimensão da prestação de serviço assume para os agricultores uma importância muito maior do que geralmente se pensa, embora muitas vezes nós, pesquisadores, inspirados em perspectivas normativistas, esperemos o contrário.

\section{Referências}

BANCO CENTRAL DO BRASIL - BCB. Anuário Estatístico do Crédito Rural 2012. Brasília, 2012. Disponível em: <http://www.bcb.gov.br/htms/creditorural/2012/pronaf. asp?idpai=RELRURAL2012>. Acesso em: 28 jan. 2015.

CEFAÏ, Daniel. Les cadres de l'action collective. In: CEFAÏ, Daniel; TROM, Danny. Les forms de l'action collective: mobilizations dans des arènes publiques. Paris, École de Hautes Études em Scineces Sociales, 2001.

. Pourquoi se mobilise-t-on? Les théories de l'action collective. Paris, La Decouverte, 2007.

. Como nos mobilizamos? A contribuição de uma abordagem pragmatista para a sociologia da ação coletiva. Dilemas. Rio de Janeiro, v. 2, n. 4, Abril/Junho 2009, pp. 11-48. 
. Como uma associação nasce para o público: vínculos locias e arena pública em torno da associação La Bellevilleuse, em Paris. In: CEFAÏ, Daniel. et al. (Orgs). Arenas públicas: por uma etnografia da vida associativa. Niterói, Editora da UFF, 2011.

CEFAÏ, Daniel; VEIGA, Felipe; MOTA, Fabio. Arenas públicas: por uma etnografia da vida associativa. In: CEFAÏ, Daniel. et al. (Orgs). Arenas públicas: por uma etnografia da vida associativa. Niterói, Editora da UFF, 2011.

COMERFORD, John C. Como uma família: sociabilidade, territórios de parentesco e sindicalismo rural. Rio de Janeiro, Relume Dumará, 2003.

GAZETA DO SUL. Jornal de Santa Cruz do Sul, Santa Cruz do Sul, RS, 12 nov. 1977.

GIUGNI, Marco; PASSY, Florence. Contentious politics in complex societies: new social movements between conflict and cooperation. In: GIUGNI, Marco; MCADAM, Doug; TILLY, Charles (Orgs.). From contention to democracy. Lanham, Rowman \& Littlefield, 1998.

GRISA, Catia; WESZ JUNIOR, Waldemar João; BUCHWEITZ, Vitor Duarte. Revisitando o Pronaf: velhos questionamentos, novas interpretações. Revista de Economia e Sociologia Rural. Piracicaba, v. 52, n. 2, Abril/Junho 2014, pp. 323-346.

GUSFIELD, Joseph. The culture of public problems. Chicago, University of Chicago Press, 1981.

IORIO, Maria Cecília. Fumicultores em greve: um estudo de representação PoliticoSindical. Dissertação de mestrado, Sociologia e Antropologia, Universidade Federal do Rio de Janeiro, 1993.

KUNRATH, Marcelo; SCHMITT, Claudia. Políticas em rede: uma análise comparativa das interdependências entre o Programa de Aquisição de Alimentos e as redes associativas no Rio Grande do Sul e na Bahia. In: $36^{\circ}$ Encontro Anual da ANPOCS. São Paulo: ANPOCS, 2012.

LIEDKE, Élida. Capitalismo e camponeses: relações entre indústria e agricultura na produção de fumo no RS. Dissertação de mestrado, Sociologia, Universidade de Brasília, 1977.

MADURO, Acácia. A prática sindical da Fetag (Federação dos Trabalhadores na Agricultura do Rio Grande do Sul). Dissertação de mestrado, Sociologia Rural, Universidade Federal do Rio Grande do Sul, 1990.

MARTINS, José. A sociabilidade do homem simples. São Paulo, Contexto, 2012.

MAUSS, Marcel. Ensaio sobre a dádiva. In: . Sociologia e Antropologia. São Paulo: $1^{\text {a }}$ ed. 1925, Cosac Naify, 2003.

MCCARTHY, John; ZALD, Mayer. Resource mobilization and social movements: a partial theory. American Journal of Sociology. Chicago, n. 82, 1977, pp. 1212-1241.

MENGEL, Alex. Tratados internacionais e disputas locais: a convenção-quadro para o controle do tabaco e as disputas entre os atores da cadeia produtiva no Brasil. Dissertação de mestrado, Ciências Sociais em Desenvolvimento, Agricultura e Sociedade, Universidade Federal Rural do Rio de Janeiro, Rio de Janeiro, 2010. 
MONTALI, Lilia. Do núcleo colonial ao capitalismo monopolista: produção de fumo em Santa Cruz do Sul. Dissertação de mestrado, Sociologia, Universidade de São Paulo, 1979.

QUIRÓS, Julieta. Por que vêm? Figuração, pessoa e experiência na política da Grande Buenos Aires. Tese de doutorado, Antropologia Social, Museu Nacional, Universidade Federal do Rio de Janeiro, 2010.

RODEGHERO, Carla. Campo $\times$ cidade: 0 discurso católico frente à modernização da agricultura no Rio Grande do Sul. Anos 90. Porto Alegre, v. 5, n. 7, Julho 1997, pp. 148-176.

SABOURIN, Eric. Sociedades e organizações camponesas: uma leitura através da reciprocidade. Porto Alegre, UFRGS, 2011.

SANTA CRUZ DO SUL. Câmara Municipal. Projeto de Lei no 245/E/2013. Santa Cruz do Sul, 11 nov. 2013.

SEYFERTH, Giralda. Identidade camponesa e identidade étnica (um estudo de caso). Anuário Antropológico. Rio de Janeiro, v. 91, pp. 31-63, 1993.

SILVA, Ari. O Significado do Trabalho na Terra do Fumo: perspectivas dos agricultores frente ao sistema integradode produção industrial em Santa Cruz do Sul/RS. Dissertação de mestrado, Desenvolvimento Regional, Universidade de Santa Cruz do Sul, 2007.

SNOW, David et al. Frame alignment processes, micromobilization and movement participation. American Sociological Review. New York, v. 51, n. 4, 464-481, 1986.

SNOW, David. Analyse de cadres et mouvements sociaux. In: CEFAÏ, Daniel; TROM, Danny. Les forms de l'action collective: mobilizations dans des arènes publiques. Paris, École de Hautes Études em SciencesSociales, 2001.

THOMPSON, Edward. Costumes em comum: estudos sobre a cultura popular tradicional. São Paulo, Cia das Letras, 1998.

VOGT, Olgário. A produção de fumo em Santa Cruz do Sul (1849-1993). Santa Cruz do Sul, Edunisc, 1997.

Recebido em: 10/08/2015

Aprovado em: 17/12/2015

\section{Como citar este artigo:}

TELÓ, Fabricio. Fumicultores e entidades de representação política: problemas públicos e engajamento em Santa Cruz do Sul/RS. Contemporânea - Revista de Sociologia da UFSCar. São Carlos, v. 6, n. 1, jan.-jun. 2016, pp. 133-157. 